\title{
The Corrosion Behavior of C-steel, Al-alloy and Pure-Cu in Red Oak Wood Extract: A Comparative Study
}

\author{
Ehteram A. Noor ${ }^{1,2}$, Azza A. Al-Ghamdi ${ }^{1,2}$, Mohamed Abdel Salam ${ }^{1 *}$ \\ ${ }^{1}$ Chemistry Department, Faculty of Science, King Abdulaziz University, P.O Box 80200-Jeddah \\ 21589, Kingdom of Saudi Arabia \\ *E-mail: masalam16@hotmail.com, mabdelsalam@kau.edu.sa
}

doi: $10.20964 / 2019.03 .08$

${ }^{2}$ Chemistry Department, Faculty of Science, University of Jeddah, P.O. Box 80327, Jeddah 21589, Saudi Arabia

Received: 15 October 2018/ Accepted: 5 December 2018 / Published: 7 February 2019

\begin{abstract}
The corrosion behavior of three metals (C-steel, Al-alloy, and Pure-Cu) in the red oak wood extract (ROWE) had been studied using weight loss (expressed as thickness loss), potentiodynamic polarization and electrochemical impedance spectroscopy. Visual and microscopic inspection of the corrosion systems was done using optical photography and SEM techniques. The results revealed that the thickness loss data fit well the kinetic power law relation $\left(\rho=K t^{n}\right)$. Depending on both values of thickness loss of one year and the instantaneous corrosion rate, the studied metals gave the following order of corrosion: $\mathrm{C}$-steel $>\mathrm{Al}$-alloy $>$ Pure-Cu. Good correlation between this order and the color and clarity of the metal/ROWE corrosion systems was obtained, where C-steel/ROWE showed the highest change in color and turbidity through the corrosion duration. Pure- $\mathrm{Cu}$ gave the lowest value for corrosion rate with exponent $\mathrm{n}<0.5$ indicating good protective properties for the corrosion product layer which showed a compact structure with no detection for microbial activity. Open structure corrosion layer $(n>0.5)$ with microbial activity was observed for both $\mathrm{C}$-steel and Al-alloy which distributed generally on the surface of the former while locally on the surface of the latter. Various electrochemical parameters were estimated and discussed. Finally, good agreement between the results obtained from various techniques confirming that $\mathrm{C}$-steel gives the highest corrosion rate while the lowest corrosion rate was recorded for Pure-Cu.
\end{abstract}

Keywords:Corrosion; Impedance; Metals, Polarization; Wood; Thickness loss

\section{$\underline{\text { FULL TEXT }}$}

(C) 2019 The Authors. Published by ESG (www.electrochemsci.org). This article is an open access article distributed under the terms and conditions of the Creative Commons Attribution license (http://creativecommons.org/licenses/by/4.0/). 